\title{
30. DOWNHOLE TEMPERATURE MEASUREMENTS AND THERMAL CONDUCTIVITIES OF SAMPLES, SITE 396 DEEP SEA DRILLING PROJECT LEG 46
}

\author{
A. J. Erickson, ${ }^{1}$ Geology Department, University of Georgia, Athens, Georgia \\ and \\ R. D. Hyndman, Pacific Geoscience Centre, Earth Physics Branch, Department of Energy, Mines, and Resources \\ Victoria, B.C., Canada
}

\section{INTRODUCTION}

Determination of the rate and distribution of heat flow through the Earth's crust provides one of the most direct sources of information on the temperature distribution within the earth. Many thousands of heat flow measurements have been made in the ocean basins by measuring the thermal gradient in the uppermost 10 meters of the sea floor using conventional oceanographic techniques (e.g., Langseth, 1965). The Deep Sea Drilling Project has provided the opportunity to measure in situ sediment temperatures to depths of hundreds of meters beneath the sea floor using the equipment and techniques described by Erickson et al. (1975). Heat flow values computed in the same region using both deep borehole and shallow sediment temperature data are in generally good agreement, confirming that the conventional measurements have not been systematically affected by variations in bottom water temperature having durations less than a few thousand years or by other near surface disturbances in the sediments.

Within the last few years, increasing attention has been paid to the question of the nature of the physical mechanisms by which heat is transmitted through the oceanic crust beneath the sediments. The discrepancy between heat flow predicted theoretically through young ocean crust using cooling lithosphere models (Parsons and Sclater, 1977) and that measured, the very high variability of the heat flow measured near the axes of active mid-ocean ridges (e.g., Sclater et al., 1974; Williams et al., 1974) and, more recently, direçt observation of active hydrothermal vents on the Galapagos Ridge (Von Herzen, personal communication, 1977), has made it clear that hydrothermal circulation in the ocean crust is an important, if not the dominant factor, in the transmission of heat through the sea floor near spreading mid-ocean ridges.

Lister (1972) proposed a model in which the circulation pattern is controlled by a combination of sea floor topography and variations in the permeability of the sea floor owing to impermeable sediment accumulation and sealing of hydrothermal vents by precipitation of secondary minerals. Heat flow measurements precisely located with respect to sea floor topography (Williams et al., 1974) support Lister's idea that elevated areas with little or no

${ }^{1}$ Present address: Eureka Resource Associates, Berkeley, California. sediment cover frequently act as chimneys through which hot water rises, whereas topographic depressions may be regions of recharge of the hydrothermal system. Our intention was to measure the temperature distribution both within the sediment and in the basaltic material beneath (Layer 2A) near a spreading ridge crest to determine with more confidence the nature and extent of heat transmission by hydrothermal circulation. We here report thermal measurements in two holes at DSDP Site 396 into 13.5-m.y.-old crust on the Mid-Atlantic Ridge.

\section{TECHNIQUES}

Three different types of downhole temperature measurements were made or attempted during DSDP Leg 46. These were:

1) Measurements of the temperature of unconsolidated sediment below the bottom of the hole, at intervals during drilling.

2) Measurement of the temperature in the bottom 30 meters of the drill hole following re-entry after bit replacement.

3) Temperature logging of the hole over an extended vertical interval.

All three types of measurements were made using a self-contained downhole temperature recorder capable of measuring temperatures with an accuracy of about $0.02^{\circ} \mathrm{C}$ and a resolution of $0.002^{\circ} \mathrm{C}$ (see Erickson et al., 1975). The temperature data are recorded on magnetic tape for lengths of time whose duration is variable depending on the sampling time interval chosen. During Leg 46, temperature measurements were made every 8,16 , and 32 seconds for periods of $1.5,3$, and 6 hours, respectively.

The recorder was inserted into the end of a modified core barrel as shown in Figure 1. Coil springs above and below the pressure case provided support and acted as shock absorbers. The pressure case was prevented from being pushed up inside the core barrel by a steel baffle, and from falling out through the drill bit by a $3 / 4$-in.-thick steel plate held in place by the core catcher subassembly.

\section{Sediment Temperature Measurements}

To measure the in situ sediment temperature a thin thermistor probe extending below the drill bit is pushed through the thermally disturbed sediment into the undisturbed sediments below the bottom of the hole. To accomplish this the core barrel containing the temperature recorder was lowered on the wireline (core barrel recovery 


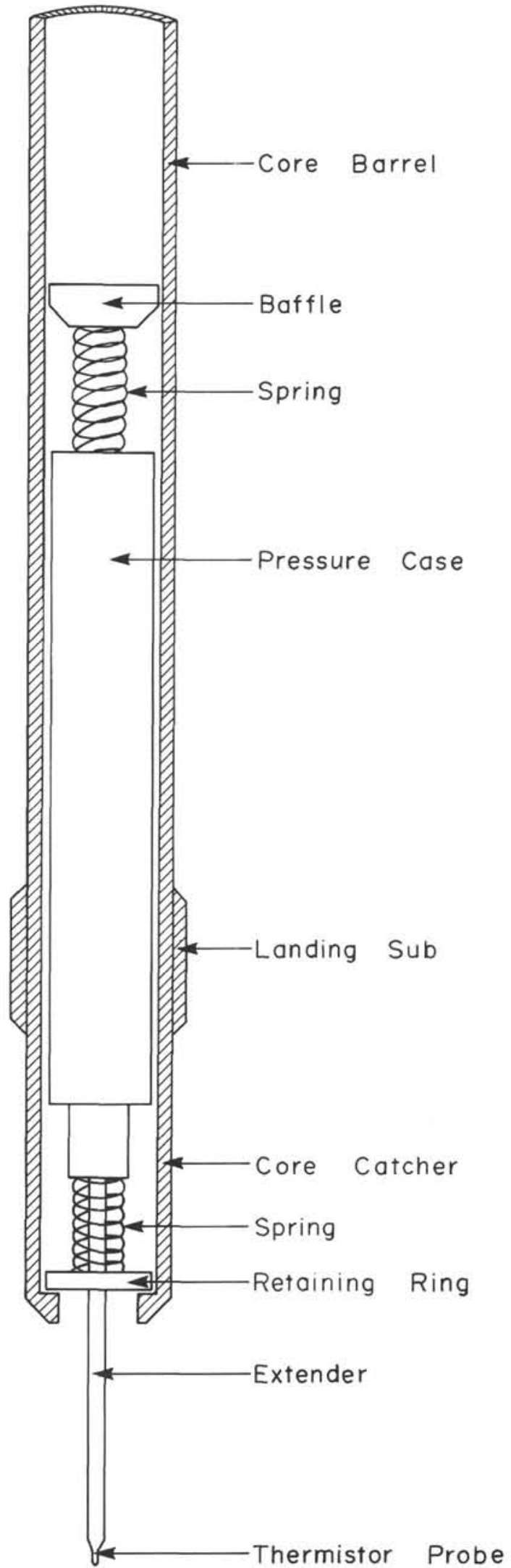

Figure 1. The downhole temperature recorder and probe assembly in the wireline core barrel. cable) and locked into the bottom hole assembly, then the drill string was slowly lowered to the bottom of the hole so that the thermistor probe was forced into thermally undisturbed sediment ahead of the drill bit. An attempt was made to close the first bumper sub (telescoping load subassembly) to help isolate the temperature probe from vertical movements of the drill string caused by ship's motion. In order for this operation to be successful, the sediment must be soft enough for probe penetration but strong enough to support the $6500-\mathrm{kg}$ weight of the drill collars below the bumper sub.

The probe was held as motionless as possible in the sediment for 15 to 20 minutes while the frictional heat generated during the penetration of the probe dissipated into the sediment and the probe approached thermal equilibrium (e.g., Erickson et al., 1975). The core barrel was then retrieved with the wireline and the recorded data played back and interpreted on board ship.

\section{Bottom Hole Measurements}

Where the sediments or basement rocks are too consolidated for the thermistor probe to penetrate, the only temperature that can be measured is that in the hole itself, which is seriously disturbed by the drilling process. With assumptions about the geometry of the hole, the thermal properties of the rock fluid, the magnitude and duration of the thermal disturbance due to drilling and circulation of drilling fluid, it is possible to correct for the drilling disturbance and obtain estimates of the in situ rock temperatures (e.g., Bullard, 1947; Jaeger, 1956, 1961; Hyndman et al., 1976). Because rock near the bottom of the hole has been subject to drilling circulation for the shortest length of time, temperatures measured there will be least disturbed and will have the most rapid return to equilibrium. However, the disturbance is still significant and temperatures should be measured as long after termination of drilling circulation as possible. When the holes are drilled with re-entry for bit replacement, the best opportunity to make useful bottom hole temperature measurements is immediately following each re-entry since considerable time is required for the re-entry operation.

Bottom hole temperatures were measured using almost the same method as for measurement of sediment temperatures. The pressure case was inserted in the core barrel which was then lowered on the wireline to the bottom of the drill string. A 30-meter length of pipe was then added to the drill string. If the drill bit is initially about 30 meters above the bottom of the hole, the drill string can be lowered slowly in 5-meter increments, allowing the temperature probe 2 or 3 minutes to come to equilibrium at each level. In this way a set of five or six temperature values can be obtained from which a local bottom hole thermal gradient can be computed. After completion of the measurement the core barrel can be retrieved as usual using the wireline.

\section{Temperature Logging}

Temperature logging techniques differ from those used to measure bottom hole temperatures only in that temperatures are measured over a substantial portion of the hole depth, rather than only near the bottom of the hole. For this operation, the wireline normally used to lower the core 
barrel must either not be used or be removed from the drill string in order to permit the addition of the drill pipe necessary to enable the bottom hole assembly to be lowered over the interval to be logged. Special equipment is needed to release the core barrel after it is lowered to the bottom of the drill string with the wireline; however, it was not available during Leg 46 . The alternative of allowing the core barrel containing the temperature probe to freefall down the drill pipe was used at Hole 396B. The speed of descent of the core barrel, with the baffle obstruction above the pressure case to impede the flow of water through the core barrel, was slightly more than $100 \mathrm{~m} / \mathrm{min}$. The drill pipe was filled with water to the level of the drill rig floor to eliminate the impact created when the core barrel strikes the water surface in the drill pipe. The instrument appears to have suffered no damage; however, this procedure probably should be used only when absolutely necessary.

\section{RESULTS}

\section{Heat Flow Measurement $1-$ Hole 396A, 58 Meters Sub-bottom}

No downhole temperature data were obtained in the borehole because the instrument did not reach the sea floor until after the end of the measurement cycle.

\section{Heat Flow Measurement $2-$ Hole 396A, 75 Meters Sub-bottom}

Although the instrument worked perfectly, the large sea swells and resultant vertical movement of the drill pipe along with too soft sediment produced a highly disturbed temperature record. Examination of Figure 2 suggests that the thermistor probe was nearly constantly in motion, with sudden temperature rises associated with frictional heating during downward movement, followed almost immediately by rapid cooling as the probe was pulled up into the cooler fluid within the borehole. The sediment at the bottom of the hole was not consolidated enough to support the lowermost bumper sub even with successive lowerings of the drill pipe by a few meters. Temperatures recorded while the probe was moving in the sediments vary between $5.61^{\circ}$ and $7.82^{\circ} \mathrm{C}$. In a few instances, it appears that the probe was stationary for periods long enough that segments of an apparent decay curve are discernible. Figure 3 shows some very speculative attempts to fit decay curves to these data points. The estimated equilibrium temperatures are between $4.8^{\circ}$ and $5.4^{\circ} \mathrm{C}$, with the lower temperature being more probable. It is possible that the gradual temperature increase of about $0.5^{\circ} \mathrm{C}$ observed during the measurement period was caused by conduction to the sensor of the frictional heat generated by the motion of the bottom hole assembly. A bottom water temperature of $3.43 \pm 0.02^{\circ} \mathrm{C}$ was estimated from temperatures recorded in the drill pipe just before the temperature probe within the drill string passed below the sea floor.

\section{Heat Flow Measurement 3-Hole 396A, 95 Meters Sub-bottom}

Heat flow measurement 3 also suffered from motion of the thermistor probe; however, the sediment was somewhat more consolidated so that longer intervals of temperature data undisturbed by movement are apparent in the temperature-time plot (Figure 4). Each of these apparently undisturbed intervals has been used to estimate an equilibrium sediment temperature (Figure 5) on the assumption that the well-recorded temperature-time decay curve of the next deeper heat flow measurement, 4 , can be used to extrapolate the short intervals recorded without disturbance during measurement 3 . Although excellent agreement exists between the form of the best decay curves recorded during measurements 3 and 4 , the estimated in situ sediment temperature of between $5.1^{\circ}$ and $5.7^{\circ} \mathrm{C}$ is slightly higher than the interpolated temperature predicted on the assumption of a linear thermal gradient between the sea floor and the reliable downhole temperature, 4 , measured at 150.5 meters sub-bottom. We suspect that the observed temperatures are again higher than the in situ sediment temperatures due to the conversion of mechanical to thermal energy at the bottom of the borehole. A bottom water temperature of $3.43 \pm 0.02^{\circ} \mathrm{C}$ also was recorded on this lowering.

\section{Heat Flow Measurement 4-Hole 396B, 150.5 Meters Sub-bottom}

As a result of firmer sediment and greatly reduced ship motion in calmer sea conditions, a reliable in situ sediment temperature of $6.11 \pm 0.02^{\circ} \mathrm{C}$ was recorded within about one meter of the sediment-basalt contact at Hole 396B (Figure 6). The thermal decay curve obtained during this measurement has been extrapolated to equilibrium using the simple 1/t method discussed by Hyndman et al. (1974) (Figure 7). As previously discussed this curve has been used to aid in the interpretation of heat flow data recorded during measurements 2 and 3 . A bottom water temperature of 3.42 $\pm 0.02^{\circ} \mathrm{C}$ was recorded on this lowering, almost identical to the previous two lowerings.

\section{Bottom Hole Measurement 5-Hole 396B}

Heat flow measurement 5 was made following termination of drilling because of unstable hole conditions and after the hole had been re-entered with a drill bit modified for use with the Schlumberger well logging equipment and a downhole seismic experiment. After freefalling the core barrel containing the heat flow probe into the bottom hole assembly, temperatures were measured for 3 minutes each at approximately 4.75 -meter increments (one-half pipe length intervals) from near the bottom of the cased portion of the drill hole in the sediments down to 340.5 meters sub-bottom where drilling problems had previously become evident. Unfortunately, the thermistor probe was bent and flooded when it encountered an obstruction after logging only the uppermost 19 meters of the uncased portion of the hole. Sufficient force was exerted on the heat flow probe to push the top coil spring through the baffle.

Correlation of the temperature-time record (Figures 8 and 9) and the log of the events occurring on the drill rig floor during the measurement suggests that valid temperature data were only obtained from the first four 4.75-meter intervals (to about 115 minutes on Figures 8 and 9), after which time the probe bent and was subject to frictional heating as it rubbed against the side of the borehole. Final failure of the 


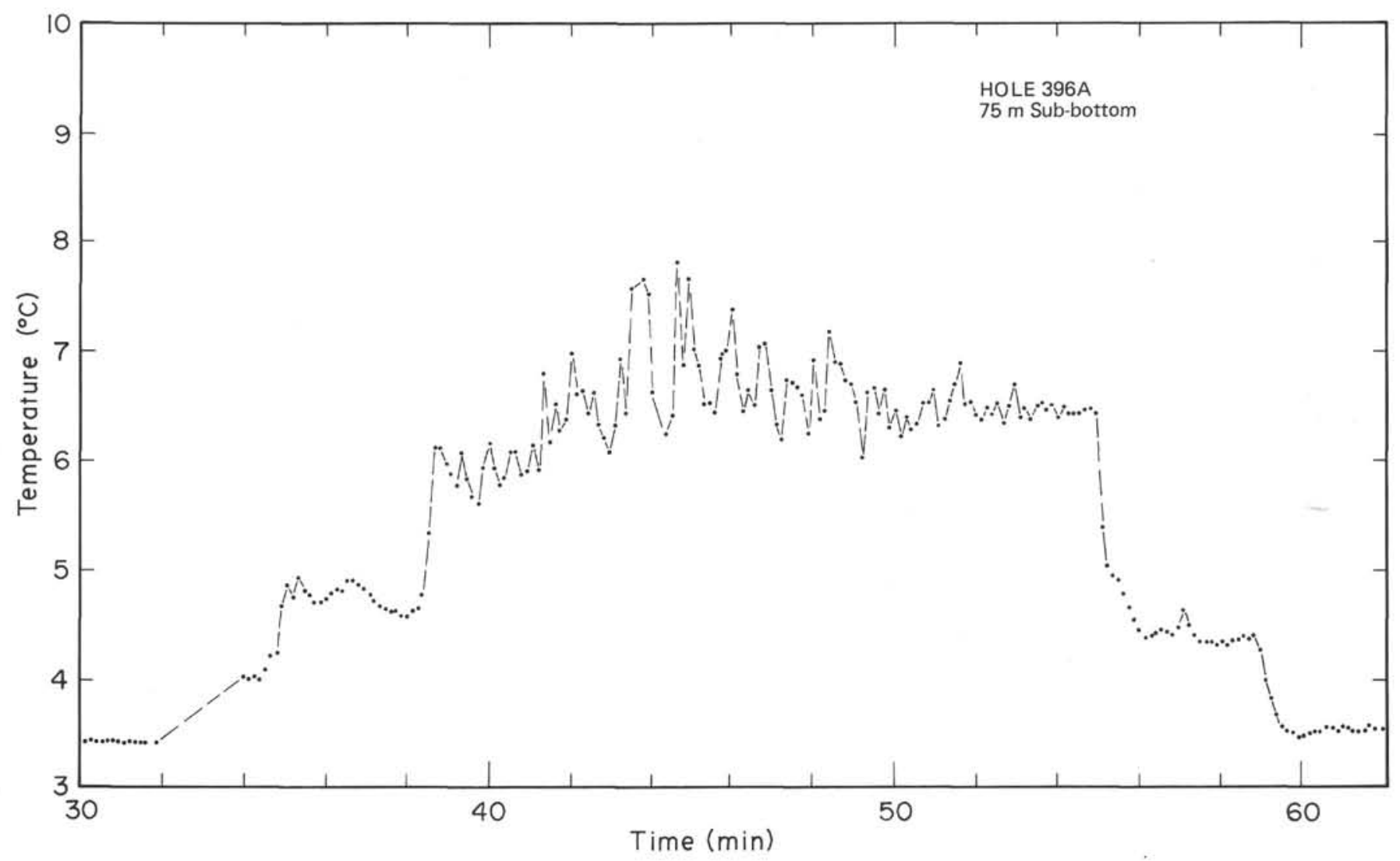

Figure 2. Plot of temperature versus time recorded during downhole temperature measurement \#2, $75 \mathrm{~m}$ sub-bottom at Hole 396A.

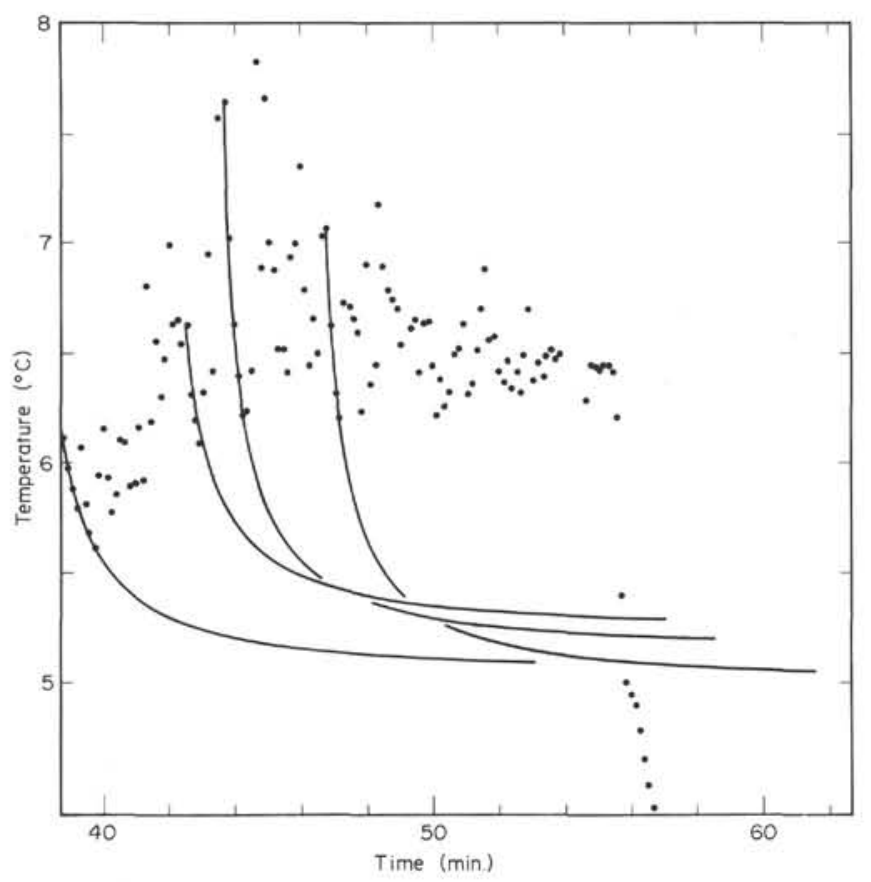

Figure 3. Extrapolation of temperature-time data observed during downhole temperature measurement \#2 using the thermal decay curve observed during measurement \#4. probe occurred at 133 minutes when the tip of the thermistor probe broke off and the probe flooded. The obstruction responsible for bending the thermistor probe occurred between 172 and 177 meters sub-bottom, only 20 to 25 meters into the basement. When the probe broke it filled with sediment, suggesting that the hole was full of sediment at that depth. For future measurements where obstructions may be encountered, temperature measurement within the drill pipe is suggested.

A temperature of $3.05 \pm 0.02^{\circ} \mathrm{C}$ was measured both within the casing and in the uncased borehole in the basaltic basement. This value has been increased by $0.47^{\circ} \mathrm{C}$ to bring the observed bottom water temperature of $2.95^{\circ} \mathrm{C}$ into agreement with the consistently recorded values of $3.42^{\circ} \mathrm{C}$ measured with the same instrument, but a different thermistor, during the preceding three heat flow measurements $(2,3$, and 4$)$. The change in calibration probably arose from the severe shock to which this thermistor was subjected. Thus borehole temperatures between 153 and 172 meters were nearly constant and only slightly $\left(0.10^{\circ} \mathrm{C}\right)$ warmer than the bottom water temperature.

\section{THERMAL CONDUCTIVITY MEASUREMENTS}

\section{Sediments}

Thermal conductivity measurements were made aboard Glomar Challenger on the sediment cores recovered from 


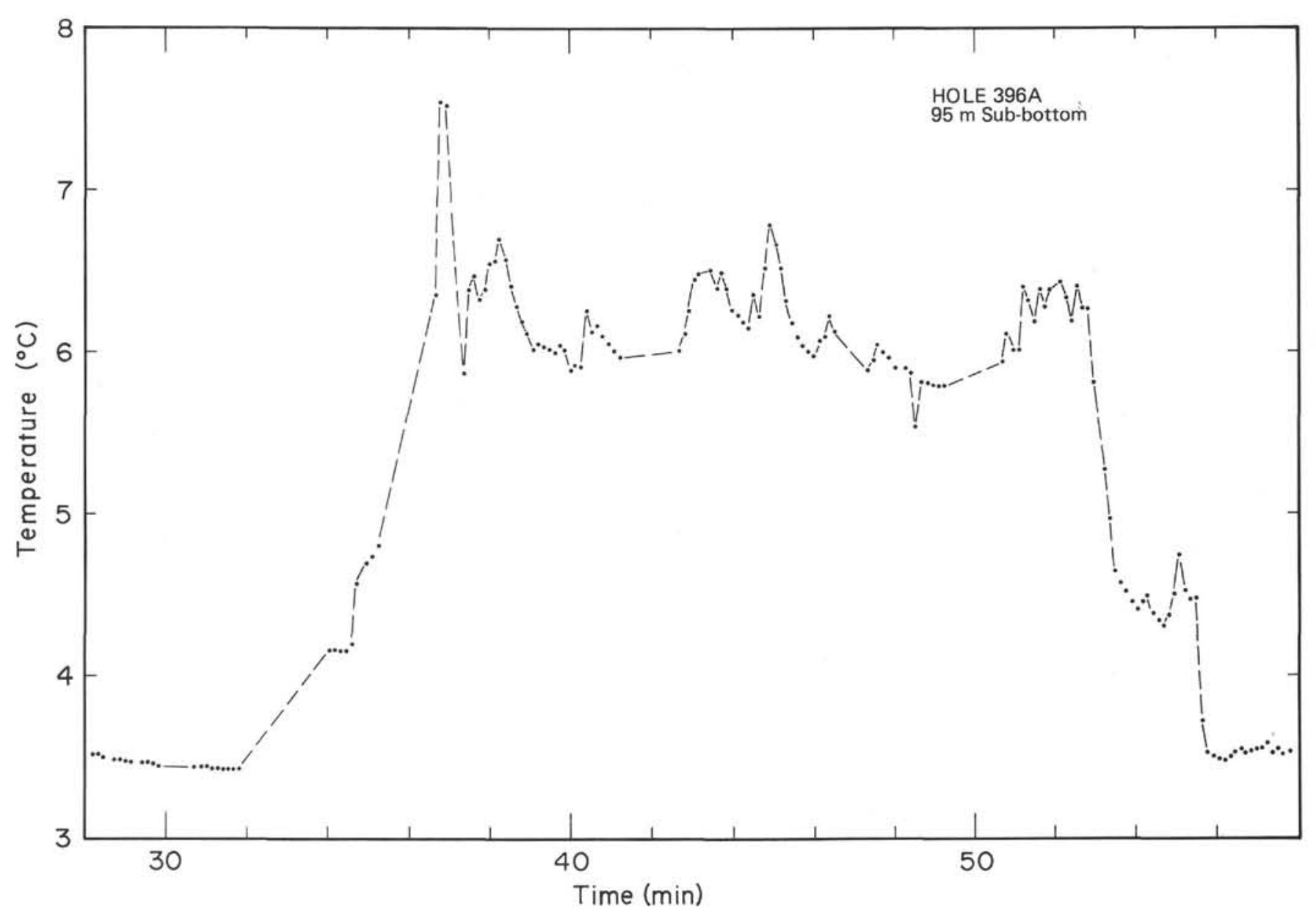

Figure 4. Plot of temperature versus time recorded during downhole temperature measurement \#3, $95 \mathrm{~m}$ sub-bottom, at Hole 396A.

the holes using the transient needle-probe method described by Von Herzen and Maxwell (1959). This method uses the rate of temperature increase as a function of time in a thin-walled hypodermic needle containing a heating element and a thermistor. The temperature increase for a constant heat input is recorded in analog form, then digitized, and a curve of the form $T=A+B t+C \ln (t)$ is fitted to the temperature $(T)$ versus time $(t)$ data using a nonlinear regression program. The value of $C$ depends on the thermal conductivity. Reduction of the data in this manner permits the removal of nearly linear temperature drift (given by the value of $B$ ) arising from the difference in ambient temperature between the sediment core and the laboratory. The needle is inserted into the sediment through small holes drilled in the plastic core liner.

The results of the sediment thermal conductivity measurements are listed in Table 1. Data from both Holes $396 \mathrm{~A}$ and 396B have been combined in Figure 10. The mean of the five conductivity values measured in a single section of severely disturbed, totally unconsolidated nanno-foram ooze recovered from just below the sediment surface at Hole $396 \mathrm{~A}$ is $2.84 \pm 0.07 \mathrm{mcal} / \mathrm{cm} \mathrm{sec}{ }^{\circ} \mathrm{C}$. The 18 conductivity values measured in sediments recovered from greater depth, 122.50 to 142.27 meters sub-bottom, in Hole $396 \mathrm{~B}$ are highly variable, with a mean and standard deviation of $3.04 \pm 0.24 \mathrm{mcal} / \mathrm{cm} \mathrm{sec}{ }^{\circ} \mathrm{C}$. This value is similar but slightly higher than the mean for previously measured carbonate sediments. Mean thermal conductivity values for each of the four sections from which data were available (Table 2), although quite variable, show no systematic variation with depth. Cores 1 and 2 at Hole 396B consist of nannofossil ooze; Core 3, with a lower conductivity, is described as marly nanofossil ooze. All cores were severely to moderately disturbed by drilling.

\section{Basalt}

The thermal conductivity and wet density of 10 basalt samples from Hole 396B were measured using a divided bar apparatus with constant temperature ends (Jessop, 1970). Values for the quartz and fused silica standards used in the apparatus were from Ratcliffe (1959). The basalt samples were in the form of discs $2.5 \mathrm{~cm}$ in diameter by $1.0 \mathrm{~cm}$ thick which were cut from small $2.5-\mathrm{cm}$-diameter cores (mini-cores) drilled from chunks of basalt. The minicores were stored in water as soon as possible after their recovery aboard D/V Glomar Challenger and kept saturated until their conductivity was measured.

The mean sample temperature was about $25^{\circ} \mathrm{C}$, and the accuracy of individual values is better than 5 per cent (Table 3). The harmonic mean conductivity is $4.08 \pm 0.05 \mathrm{mcal} / \mathrm{cm}$ sec ${ }^{\circ} \mathrm{C}$, very similar to that measured previously on sea floor basalts (e.g., Hyndman and Drury, 1976). The thermal 


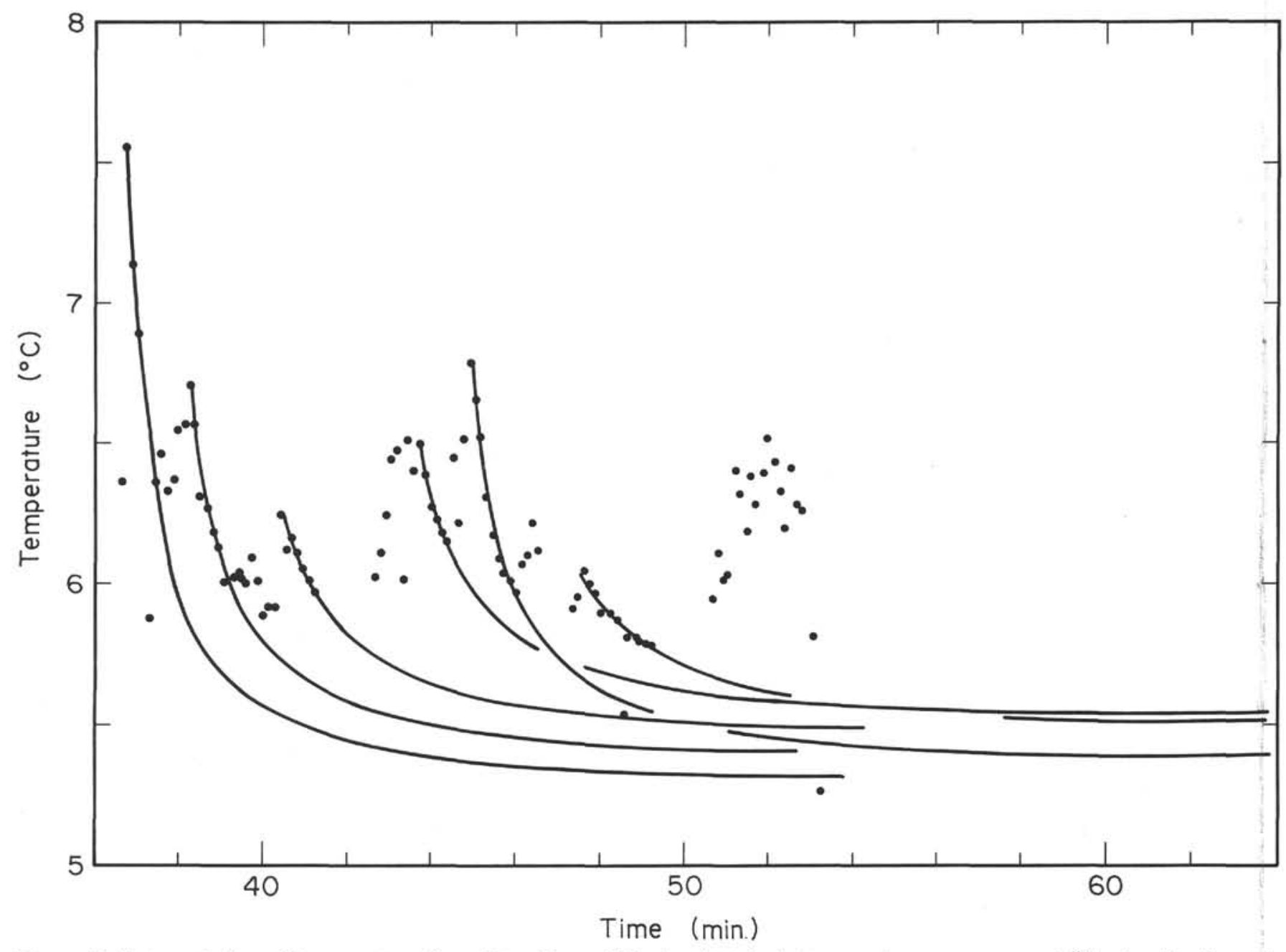

Figure 5. Extrapolation of temperature-time data observed during downhole temperature measurement \#3 using the thermal decay curve observed during measurement \#4.

conductivities measured on basalt samples have been plotted as a function of depth in Figure 10. Although clearly higher than conductivity values measured in the sediments above, there is no obvious relationship of the measured conductivities with depth. The in situ conductivity of the upper crust may be significantly lower than this mean because of the presence of extensive voids and fractures not represented in the small laboratory specimens, perhaps as low as $3.5 \mathrm{mcal} / \mathrm{cm} \mathrm{sec}{ }^{\circ} \mathrm{C}$. The effect of the difference between laboratory and in situ temperature and pressure on the measured thermal conductivity should be negligible (see Hyndman and Drury, 1976).

\section{INTERPRETATIONS}

\section{Heat Flow Calculations}

From the borehole temperatures measured in the sedimentary portion of Holes 396A and 396B (Table 4) the average thermal gradient is $17.8 \pm 1.0^{\circ} \mathrm{C} / \mathrm{km}$ between the sea floor and the sediment-basalt interface (Figure 11). This value is based upon the three bottom water temperature measurements in the drill pipe at the sea floor, and upon the reliable temperature measured at 150.5 meters sub-bottom. No correction of the observed mean conductivity (3.04 $\pm 0.24 \mathrm{mcal} / \mathrm{cm} \mathrm{sec}{ }^{\circ} \mathrm{C}$ ) to in situ temperature and pressure conditions at sub-bottom was made as the two effects approximately cancel and the variability in the conductivity data is much larger than either the pressure or temperature correction. This thermal gradient and mean thermal conductivity give a heat flow estimate of $0.54 \pm 0.07$ $\mu \mathrm{cal} / \mathrm{cm}^{2} \mathrm{sec}$ through the sediment at Site 396 . A somewhat higher value is obtained using the gradient between the seafloor and the less reliable temperature measured at 95 meters sub-bottom.

During the site survey for Site 396 two heat flow measurements were made in the same sediment pond using a standard Ewing-type heat flow instrument with outrigger probes mounted on a piston corer ( $\mathrm{J}$. Crowe, personal communication, 1977, Purdy et al., 1978). Heat flow values of 0.27 and of less than $0.7 \mu \mathrm{cal} / \mathrm{cm}^{2} \mathrm{sec}$ were measured, in agreement with the low value of 0.54 $\mu \mathrm{cal} / \mathrm{cm}^{2} \mathrm{sec}$ measured in the borehole.

\section{Basement Temperatures}

The measurement of a nearly constant temperature of only $3.05^{\circ} \mathrm{C}$ ( corrected to $3.52^{\circ} \mathrm{C}$ as previously discussed) just below the sediment-basalt interface was surprising for several reasons. Firstly, downward extrapolation of the 


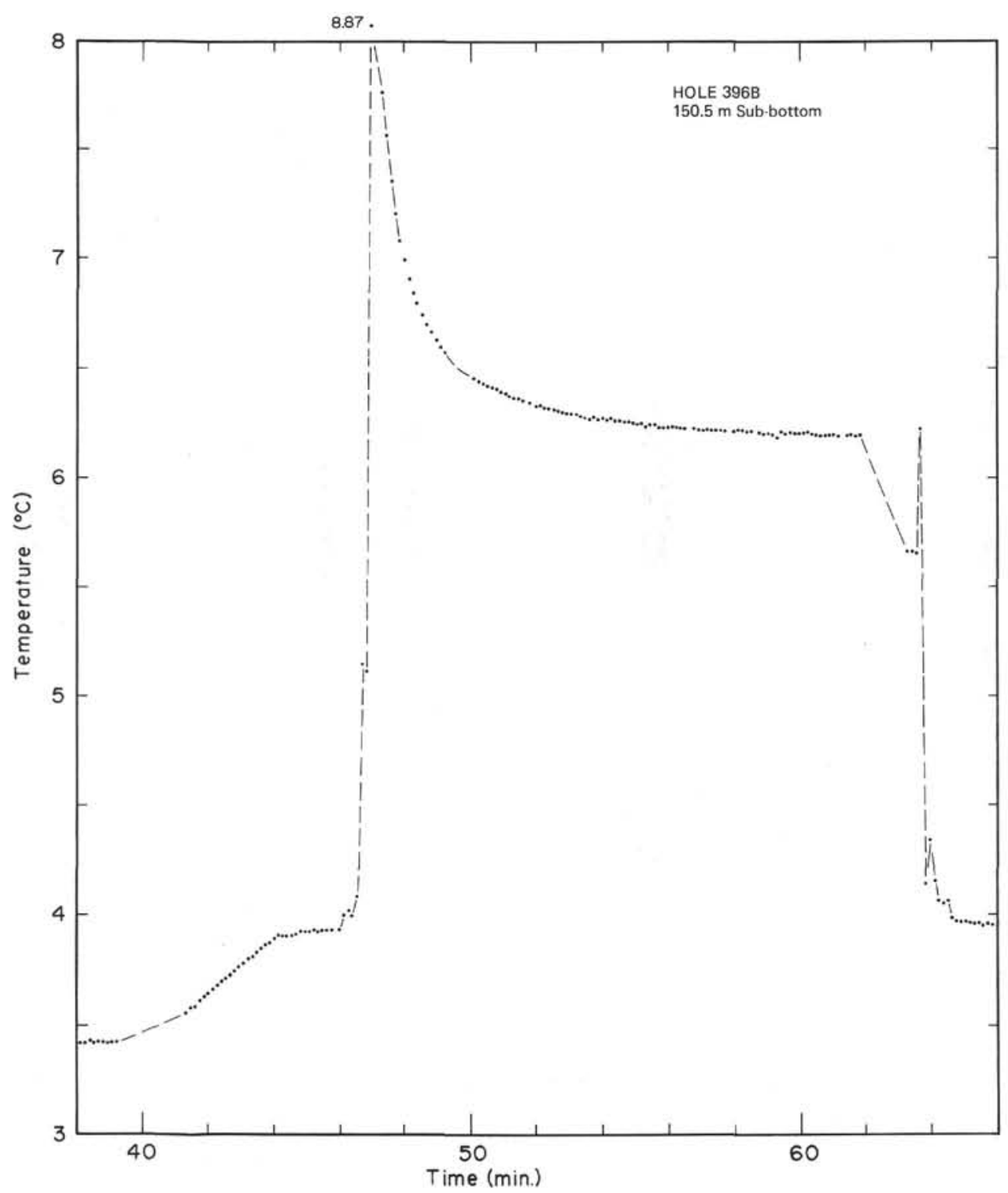

Figure 6. Plot of temperature versus time recorded during downhole temperature measurement \#4, $150.5 \mathrm{~m}$ sub-bottom, at Hole $396 \mathrm{~B}$.

temperatures in the sediment using the mean basalt thermal conductivity gives a temperature increase of $0.25^{\circ} \mathrm{C}$ expected in the borehole between 153 and 172 meters sub-bottom. The observed increase was less than $0.02^{\circ} \mathrm{C}$. Secondly, a reliable sediment temperature of $6.11^{\circ} \mathrm{C}$ was determined within about a meter of the top of the section through which the temperature was logged. The only reasonable explanations for the result are either that the drilling circulation thermal disturbance had not significantly decayed or that seawater is flowing down the borehole into the permeable basaltic clastic layers encountered deeper in the borehole (see Site Chapter), this bathymetric low perhaps being a hydrothermal recharge area.

The following argument shows that the anomalously low temperature measured in the upper 19 meters of the basement cannot be attributed to cooling of the rocks due to circulation of drilling fluid. The temperature in the borehole at any depth will be a function of (1) the initial temperature of the wall rock at that depth, (2) the temperature of the circulating fluid (close to the bottom water temperature), (3) the history of circulation, (4) the length of time that the borehole has been undisturbed since last circulation, (5) the thermal properties of the wall rock and borehole contents, and (6) the size of the borehole.

The response of the borehole to a particular drilling history can be approximated by assuming (1) that the circulation of cool seawater through the hole is equivalent to keeping the walls of the borehole at the temperature of the circulating fluid whenever circulation is in progress (e.g., Jaeger, 1956, 1961); or less accurately by assuming (2) that heat is removed from the rocks surrounding the borehole at a constant rate during circulation (e.g., Bullard, 1947). The second set of boundary conditions will overestimate the thermal disturbance caused by circulation since as circulation continues for longer and longer times, the wall rocks will gradually cool and will lose heat at a lower rate 


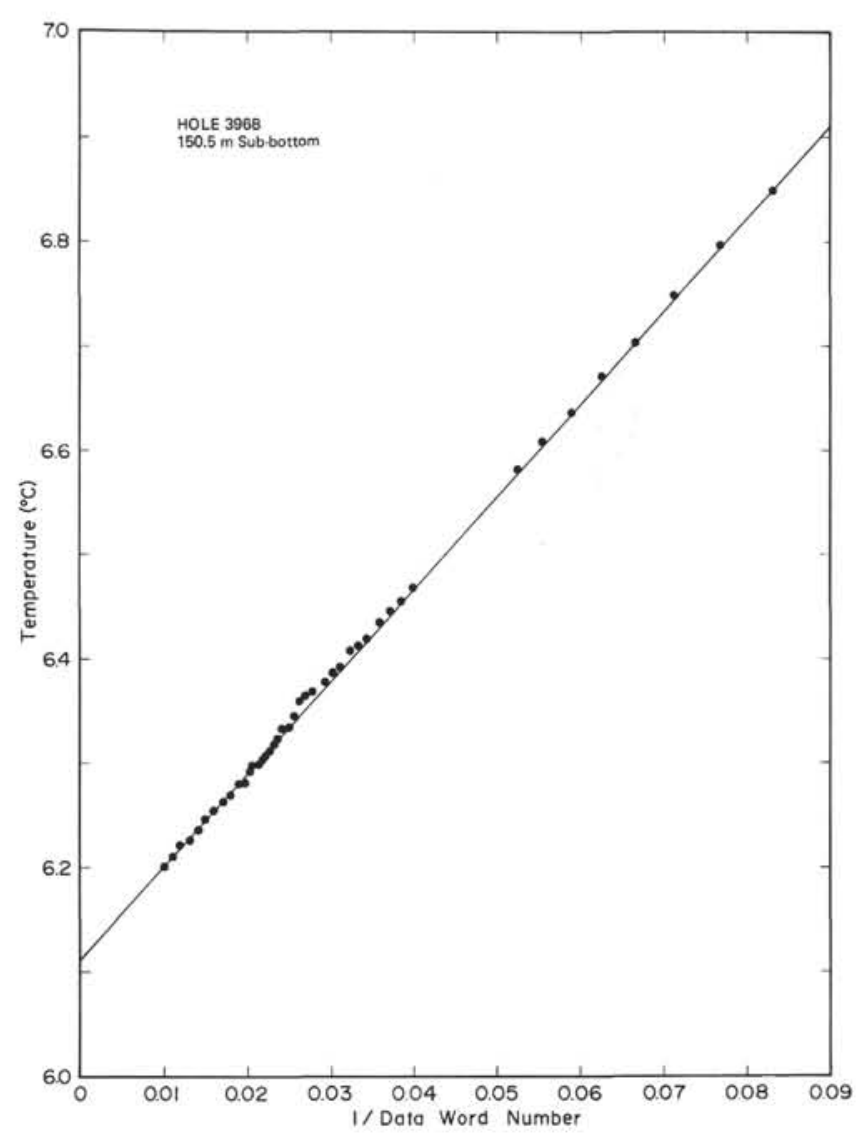

Figure 7. Plot of observed temperature versus the inverse of elapsed time (in number of $8 \mathrm{sec}$. long data cycles) since the temperature probe penetrated the sediment at the bottom of the hole. The linear curve permits accurate extrapolation of the disturbance decay (Figure 6) to an equilibrium temperature.

than they did initially when the temperature difference between the circulating water and wall rocks was at a maximum.

The total drilling and circulation time from the first core in basalt was 16.5 days, interspersed with long periods of non-circulation during re-entry operations, and other delays. By assuming that circulation was continuous the maximum thermal disturbance can be calculated. The hole was permitted to equilibrate for about 37.5 hours from the time the last core was obtained until the temperature logging. This time is much longer than the thermal response time of the borehole fluid so that equilibration of the material in the borehole to wall rock temperature can be assumed.

Using the simple approximate theory of Bullard (1947), a minimum of 40 per cent of the disturbance should have decayed so that the observed temperature in the borehole should be at least $1.1^{\circ} \mathrm{C}$ warmer than the temperature of the drilling fluid, rather than the $0.10^{\circ} \mathrm{C}$ observed.

We thus conclude that water is flowing down the hole from the sea floor, with only slight warming due to heat flow from the walls of the hole, and is then entering the highly permeable layers of basaltic sand and gravel encountered between about 310 and 405 meters sub-bottom. If this conclusion is correct, at least after having penetrated by drilling, the porous layers became part of a hydro-thermal circulatory system, possibly involving basement outcrops which act as chimneys for rising hot water which is replaced through or near the edges of sediment-covered basement lows by the slow downward diffusion of cool water. An illustrative schematic cross-section is shown in Figure 12.

\section{CONCLUSIONS}

Temperature measurements in the sedimentary portion of the borehole at Site 396 demonstrate a low approximately linear thermal gradient. A heat flow of $0.54 \mu \mathrm{cal} / \mathrm{cm}^{2} \mathrm{sec}$ is calculated. Although this value is much lower than the heat flow theoretically expected $\left(3.1 \mu \mathrm{cal} / \mathrm{cm}^{2} \mathrm{sec}\right)$ through ocean crust of this age (13.5 m.y.) on the basis of cooling lithosphere models (Parsons and Sclater, 1977), it is in agreement with the other low values observed in the same sediment pond, and is consistent with the generally low, but variable heat flow observed through sediment ponds in regions of rough topography and young crust. The low heat flow through the sediment is attributed to the effects of hydrothermal circulation within the fractured, permeable basement beneath the sediment, rather than to fluid movement within the sediment itself.

The observation of low heat flow in the sediment and nearly constant temperatures only slightly greater than that of the bottom water in the basement portion of the borehole is nearly identical with the results obtained at Site 335 during Leg 37 (Hyndman et al., 1976). Our interpretation of the data at Site 396 is similar to that proposed for Site 335, that when the drill bit penetrated the relatively impermeable sediment cover it initiated the downward flow of seawater through the hole into the highly permeable, basement rocks, particularly into the glass-rich basaltic sand and gravel layers encountered below about 310 meters sub-bottom, 160 meters below the sediment.

It is perhaps significant that at both Sites 335 and 396, located in oceanic crust of approximately the same age (16.5 and 13.5 m.y., respectively), strong evidence exists for flow of seawater down the borehole, whereas for Sites 332 and 334, drilled 3.5- and 8.9-m.y.-old crust, no such downward flow is indicated. One possible interpretation of this observation is that the permeability of the basaltic basement increases with age near the ridge crest, and that highly permeable layers of basaltic sand and gravel are less common in basement younger than 9 or 10 million years. This possibility is in agreement with suggestions by Dick et al. (this volume) that clastic material is formed by tectonic brecciation, erosion, transport, and deposition on the ridge flanks away from the median valley.

\section{ACKNOWLEDGMENTS}

We wish to express our appreciation for the assistance provided by the Deep Sea Drilling Project technical staff in making the temperature measurements. We also thank Dr. A. M. Jessop for arranging the thermal conductivity measurements on the basalt samples. Contribution of the Earth Physics Branch. 


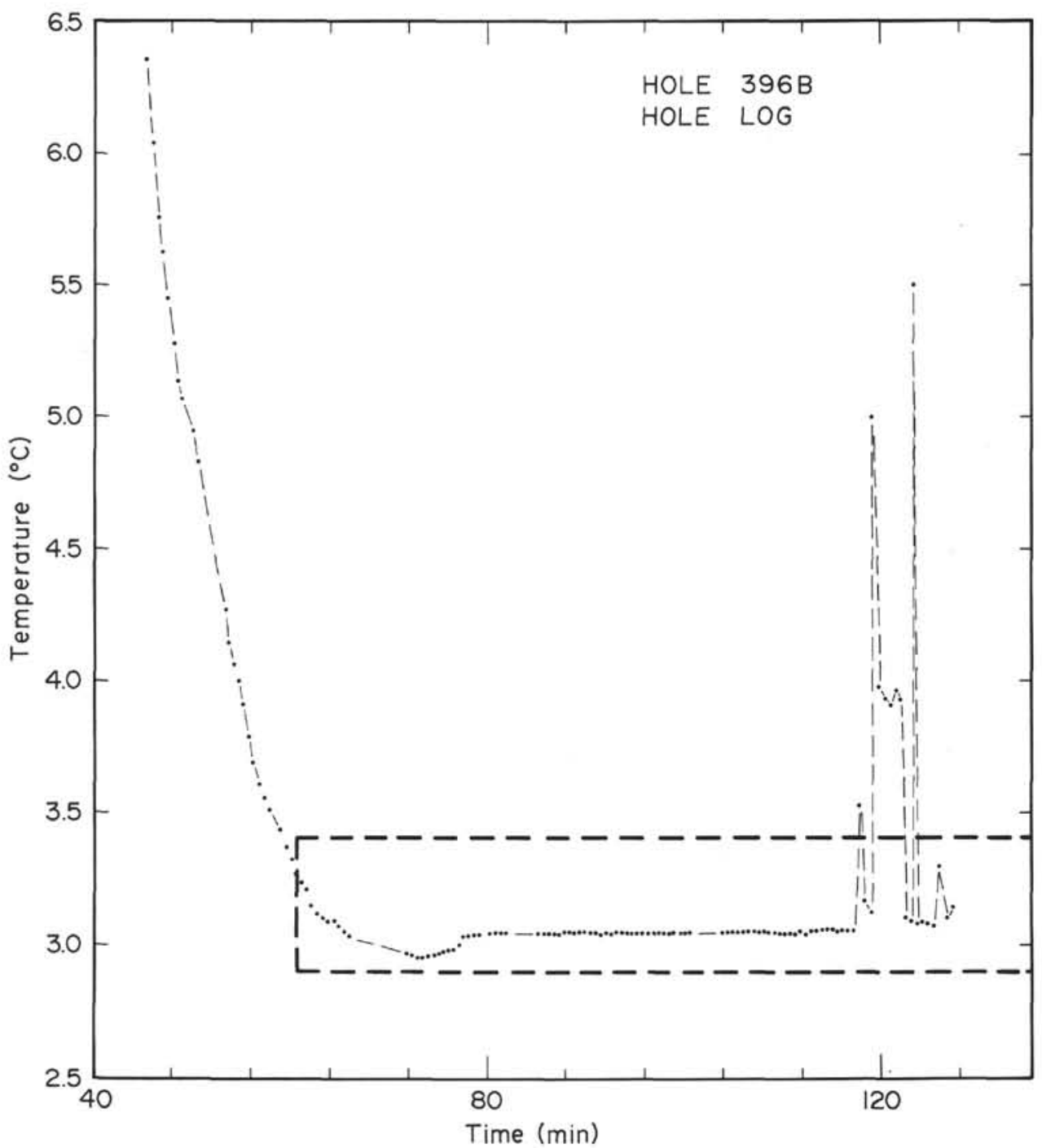

Figure 8. Plot of temperature versus time recorded during downhole temperature measurement \#6 in Hole 396B. Temperatures were measured every $4.75 \mathrm{~m}$ from the base of the cased portion of the borehole until the thermistor probe bent (117 min.) Erratic temperatures between 117 and 128 minutes are believed to be due to frictional heating of the probe as it scraped up and down the wall of the borehole prior to finally flooding at $128 \mathrm{~min}$.

\section{REFERENCES}

Bullard, E. C., 1947. The time necessary for a borehole to attain temperature equilibrium, Mon. Notic. Roy. Astron. Soc., Geophys. Suppl., v. 5, p. 127-130.

Erickson, A. J., Von Herzen, R. P., Sclater, J. C., Girdler, R. W., Marshall, B. V., and Hyndman, R. D., 1975. Geothermal measurements in deep-sea drill holes, J. Geophys. Res., v. 80 , p. $2515-2528$.

Hyndman, R. D. and Drury, M. J., 1976. The physical properties of oceanic basement rocks from deep drilling on the mid-Atlantic ridge, J. Geophys. Res., v. 81, p. 4042-4052.

Hyndman, R. D., Erickson, A. J., and Von Herzen, R. P., 1974. Geothermal measurements on DSDP Leg 26: In Davis, T. A., Luyendyk, B. P., et al., Initial Reports of the Deep Sea Drilling Project, v. 26: Washington (U.S. Government Printing Office), p. 451-463.

Hyndman, R. D., Von Herzen, R. P., Erickson, A. J., and Jolivet, J., 1976. Heat flow measurements in deep crustal holes on the mid-Atlantic ridge, J. Geophys. Res., v. 81, p. $4053-4060$.

Jaeger, J. C., 1956. Numerical values for the temperature in radial heat flow, J. Math. Phys., v. 34, p. 316-321. , 1961. The effect of the drilling fluid on temperatures measured in boreholes, J. Geophys. Res., v. 66, p. 563-569.

Jessop, A. M., 1970. The effect of environment on divided bar measurements, Tectonophysics, v. 10, p. 39.

Langseth, M. G., 1965. Techniques of measuring heat flow through the ocean floor: In Lee, W. H. K (Ed.), Terrestrial heat flow, Washington (American Geophysical Union), p. $58-77$.

Lister, C. R. B., 1972. On the thermal balance of a mid-ocean ridge, Geophys. J., v. 26, p. 515-535.

Parsons, B. and J. G. Sclater, 1977. An analysis of the variation of ocean floor bathymetry and heat flow with age, J. Geophys. Res., v. 82, p. 803-827.

Purdy, G. M., Schouten, H., Crowe, J., Barrett, D. L., Falconer, R. K. H., Litvin, V. M., Udintsev, G. B., Marova, N. A., 


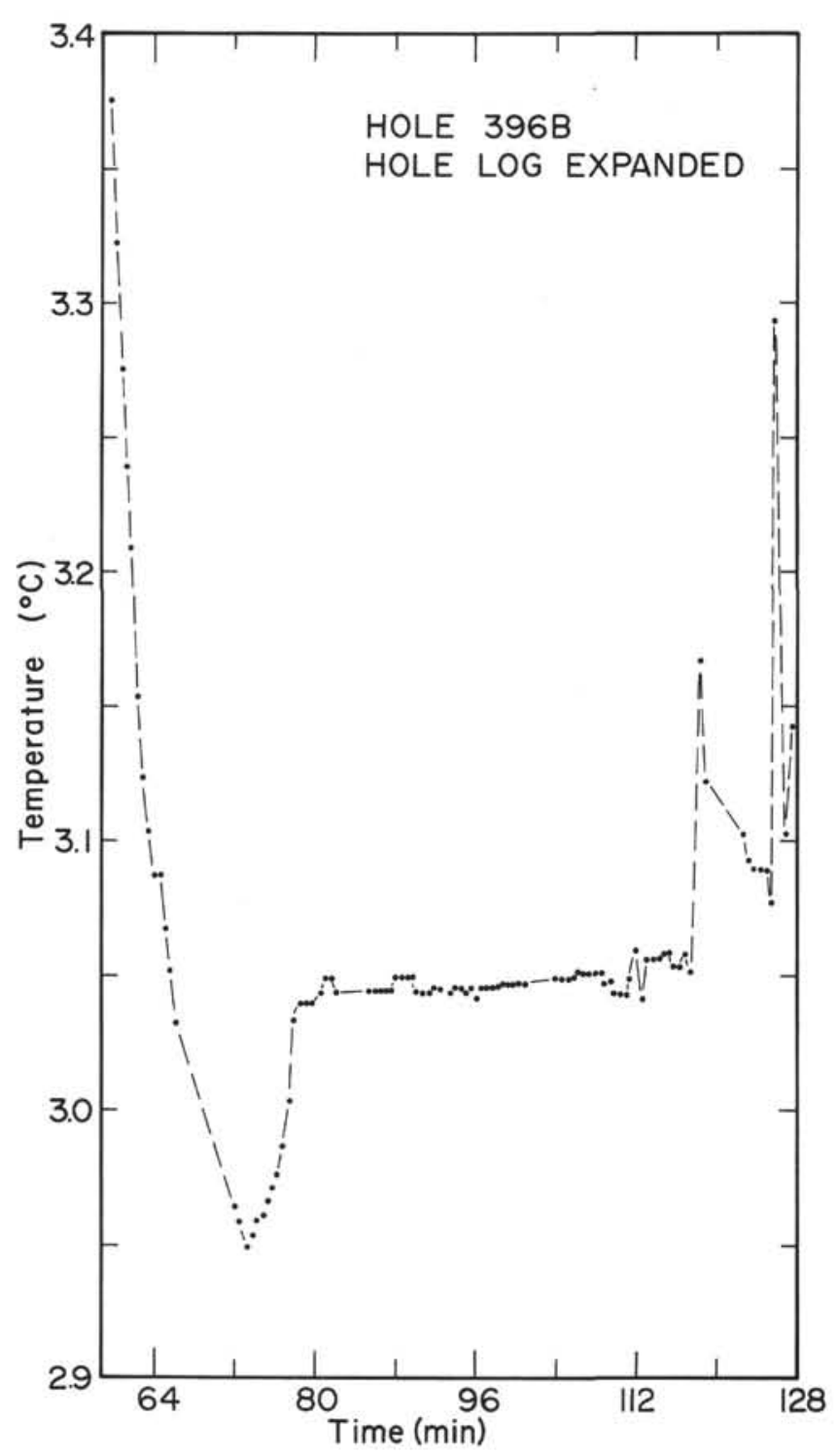

Figure 9. An explanded scale plot of data in Figure 8.

Valyashko, G. M., Markushevich, V. M., and Zdoroven, V. V., 1978. IPOD Site 6:A Site Survey. In Melson, W. G., Rabinowitz, P. D., et al., Initial Reports of the Deep Sea
TABLE 1

Thermal Conductivity Values Measured in Sediments Recovered From Holes 396A and 396B

\begin{tabular}{ccc}
\hline $\begin{array}{c}\text { Sample } \\
\text { (Interval in cm) }\end{array}$ & $\begin{array}{c}\text { Depth } \\
(\mathrm{m})\end{array}$ & $\begin{array}{c}\text { Conductivity } \\
\left(\mathrm{mcal}^{\mathrm{cm} \mathrm{sec}}{ }^{\circ} \mathrm{C}\right)\end{array}$ \\
\hline Hole 396A & & \\
$1-1,106$ & 1.04 & 2.95 \\
$1-1,115$ & 1.15 & 2.78 \\
$1-1,122$ & 1.22 & 2.80 \\
$1-1,131$ & 1.31 & 2.76 \\
$1-1,140$ & 1.40 & 2.89 \\
& & \\
Hole 396B & & \\
$1-1,50$ & 122.50 & 3.27 \\
$1-1,66$ & 122.66 & 3.05 \\
$1-1,80$ & 122.80 & 3.07 \\
$1-1,112$ & 123.12 & 3.05 \\
$1-1,135$ & 123.35 & 3.01 \\
$1-2,10$ & 123.60 & 2.70 \\
$1-2,18$ & 123.68 & 2.75 \\
$1-2,25$ & 123.75 & 2.95 \\
$2-1,53$ & 132.03 & 3.51 \\
$2-1,61$ & 132.11 & 3.38 \\
$2-1,79$ & 132.29 & 3.30 \\
$2-1,100$ & 132.50 & 3.03 \\
$2-1,119$ & 132.69 & 2.68 \\
$2-1,132$ & 132.82 & 3.15 \\
$3-1,76$ & 141.76 & 2.86 \\
$3-1,90$ & 141.90 & 2.67 \\
$3-1,106$ & 142.06 & 2.96 \\
$3-1,127$ & 142.27 & 3.29 \\
\hline & &
\end{tabular}

Drilling Project, Volume 45: Washington (U.S. Government Printing Office).

Ratcliffe, E. H., 1959. Thermal conductivities of fused and crystalline quartz, British J. Appl. Phys., v. 10, p. 22.

Sclater, J. G., Von Herzen, R. P., Williams, D. L., Anderson, R. N. and Klitgord, K. D., 1974. The Galapagos spreading center: Heat flow low on the north flank, Geophys. J., v. 38, p. 609-625.

Von Herzen, R. P. and Maxwell, A. E., 1959. The measurement of thermal conductivity of deep-sea sediments by a needle probe method, J. Geophys. Res., v. 64, p. 1557-1563.

Williams, D. L., Von Herzen, R. P., Sclater, J. G., and Anderson, R. N., 1974. The Galapagos spreading center: Lithospheric cooling and hydrothermal circulation, Geophys. J., v. 38 , p. 587-608. 
Thermal Conductivity ( $\mathrm{mcal} / \mathrm{cm} \mathrm{sec}{ }^{\circ} \mathrm{C}$ )

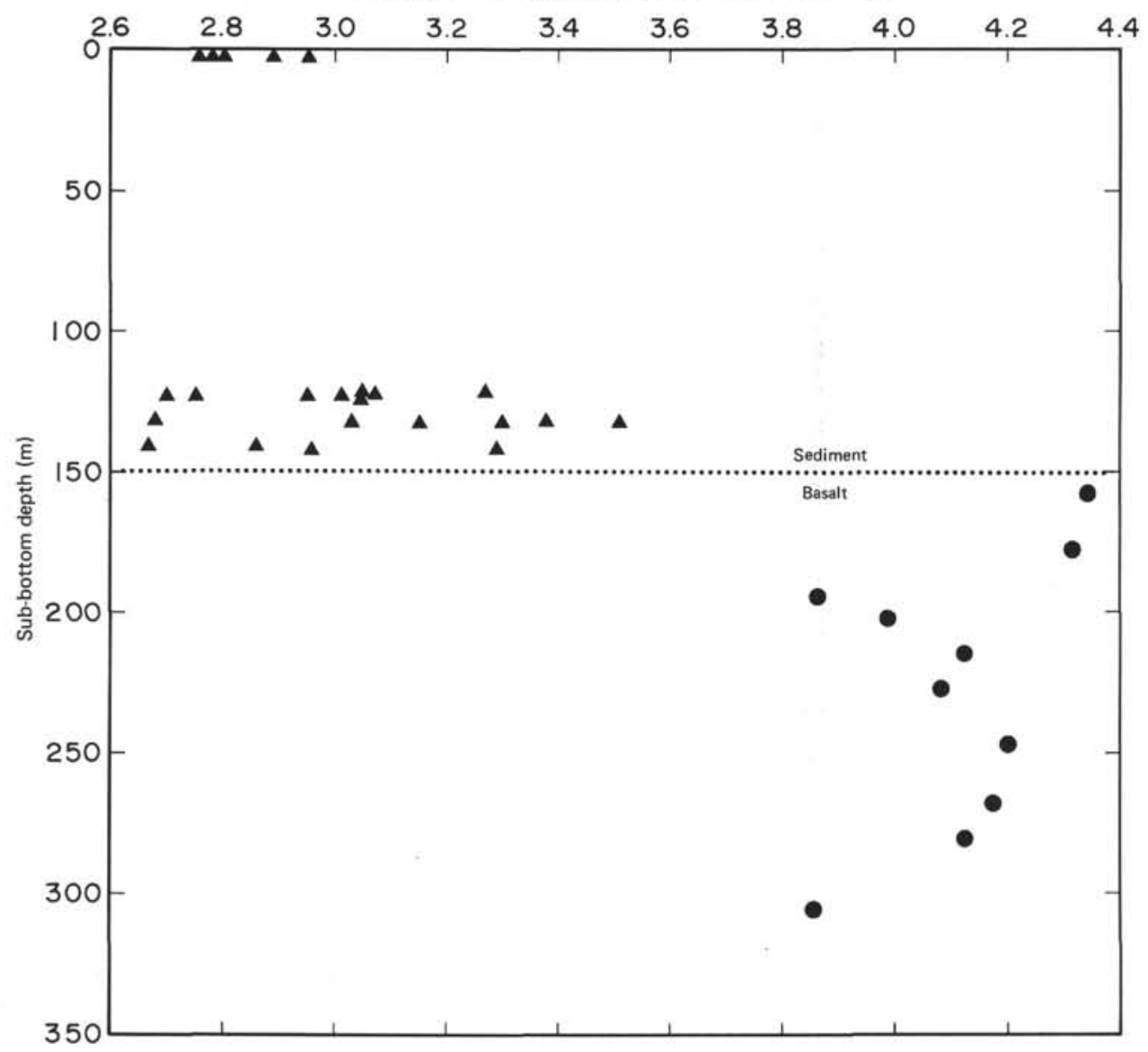

Figure 10. Plot of thermal conductivity versus sub-bottom at Site 396. Data obtained from sediments at Hole $396 \mathrm{~A}$ are shown as squares; the balance of the data (shown as circles) are from Hole $396 B$.

TABLE 2

Mean and Standard Deviation of the Thermal Conductivity Values Measured on Sections of Sediment Cores Recovered From Holes $396 \mathrm{~A}$ and 396B

\begin{tabular}{ccccc}
\hline & & \multicolumn{4}{c}{ Conductivity } \\
Coreal/cm sec & \\
Core & Section & Mean & S. D. & N \\
\hline Hole 396A & & & & \\
1 & 1 & 3.09 & 0.09 & 5 \\
Hole 396B & & & & \\
1 & 2 & 2.80 & 0.11 & 3 \\
2 & 1 & 3.15 & 0.27 & 6 \\
3 & 1 & 2.95 & 0.22 & 4 \\
\hline
\end{tabular}

TABLE 3

Thermal Conductivity and Wet Density of Pieces of Basalt Recovered From Hole 396B

\begin{tabular}{lccc}
\hline $\begin{array}{c}\text { Sample } \\
\text { (Interval in cm) }\end{array}$ & $\begin{array}{c}\text { Depth } \\
(\mathrm{m})\end{array}$ & $\begin{array}{c}\text { Conductivity } \\
\left(\mathrm{mcal} / \mathrm{cm} \mathrm{sec}^{\circ} \mathrm{C}\right)\end{array}$ & $\begin{array}{c}\text { Wet Density } \\
(\mathrm{g} / \mathrm{cc})\end{array}$ \\
\hline $5-1,61-63$ & 157.62 & 4.32 & 2.61 \\
$7-3,9-11$ & 177.10 & 4.32 & 2.80 \\
$9-2,29-41$ & 194.90 & 3.86 & 2.66 \\
$10-1,57-59$ & 203.08 & 3.98 & 2.83 \\
$12-1,103-105$ & 215.54 & 4.12 & 2.82 \\
$14-2,73-75$ & 227.74 & 4.08 & 2.82 \\
$16-2,71-73$ & 246.72 & 4.20 & 2.84 \\
$17-1,69-71$ & 268.70 & 4.18 & - \\
$20-3,137-139$ & 290.87 & 4.13 & 2.75 \\
$22-1,45-47$ & 305.96 & 3.86 & 2.75 \\
\hline
\end{tabular}

TABLE 4

Downhole Temperature Data Used in Calculating the Steady State Geothermal Gradient in the Sediment at Site 396

\begin{tabular}{ccrcl}
\hline Measurement & Hole & Depth $(\mathrm{m})$ & Temperature $\left({ }^{\circ} \mathrm{C}\right)$ & \multicolumn{1}{c}{ Remarks } \\
\hline 1 & 396A and B & $0.0 \pm 5.0$ & $3.43 \pm 0.02$ & Water temperature \\
2 & $396 \mathrm{~A}$ & $75.0 \pm 1.0$ & 4.8 to 5.4 & Unreliable \\
3 & $396 \mathrm{~A}$ & $95.0 \pm 1.0$ & 5.1 to 5.5 & Unreliable \\
4 & $396 \mathrm{~B}$ & $150.0 \pm 1.0$ & $6.11 \pm 0.02$ & Excellent \\
\hline
\end{tabular}




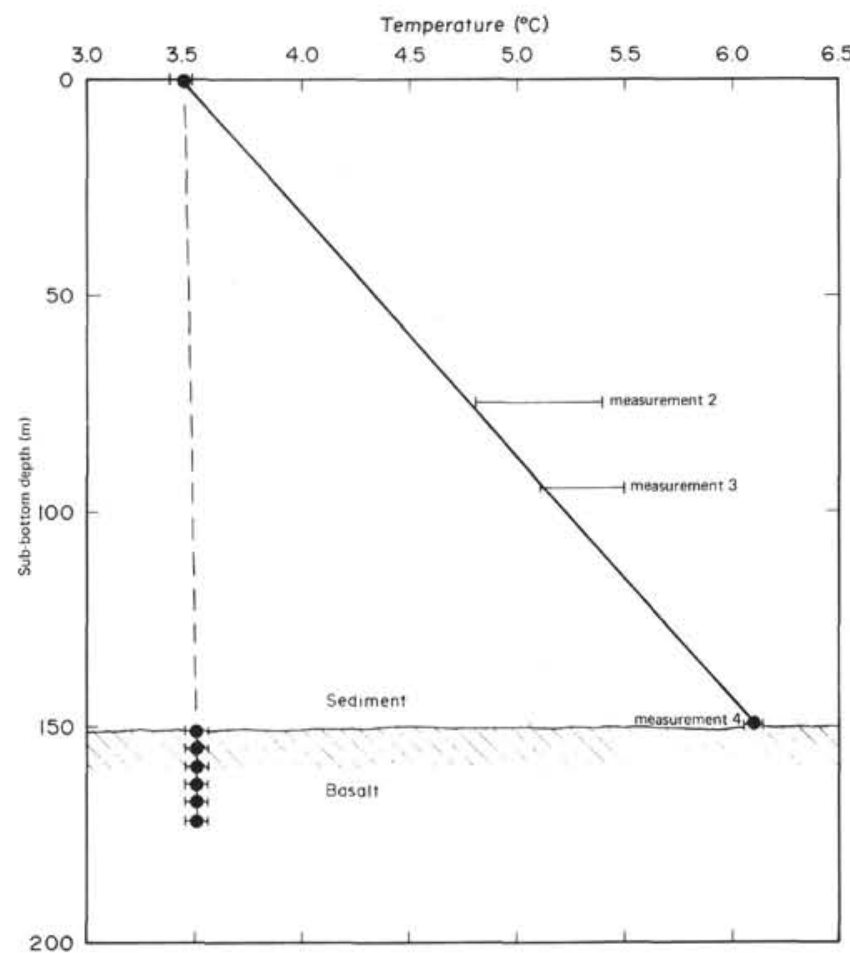

Figure 11. Plot of downhole temperatures measured in Holes 396A (\#2, \#3) and 396B (\#4) versus subbottom depth. The error bars shown are subjective estimates of the uncertainty in in situ sediment temperature. Temperature values in the basalt were logged in the water and mud filled, uncased portion of the borehole following re-entry.

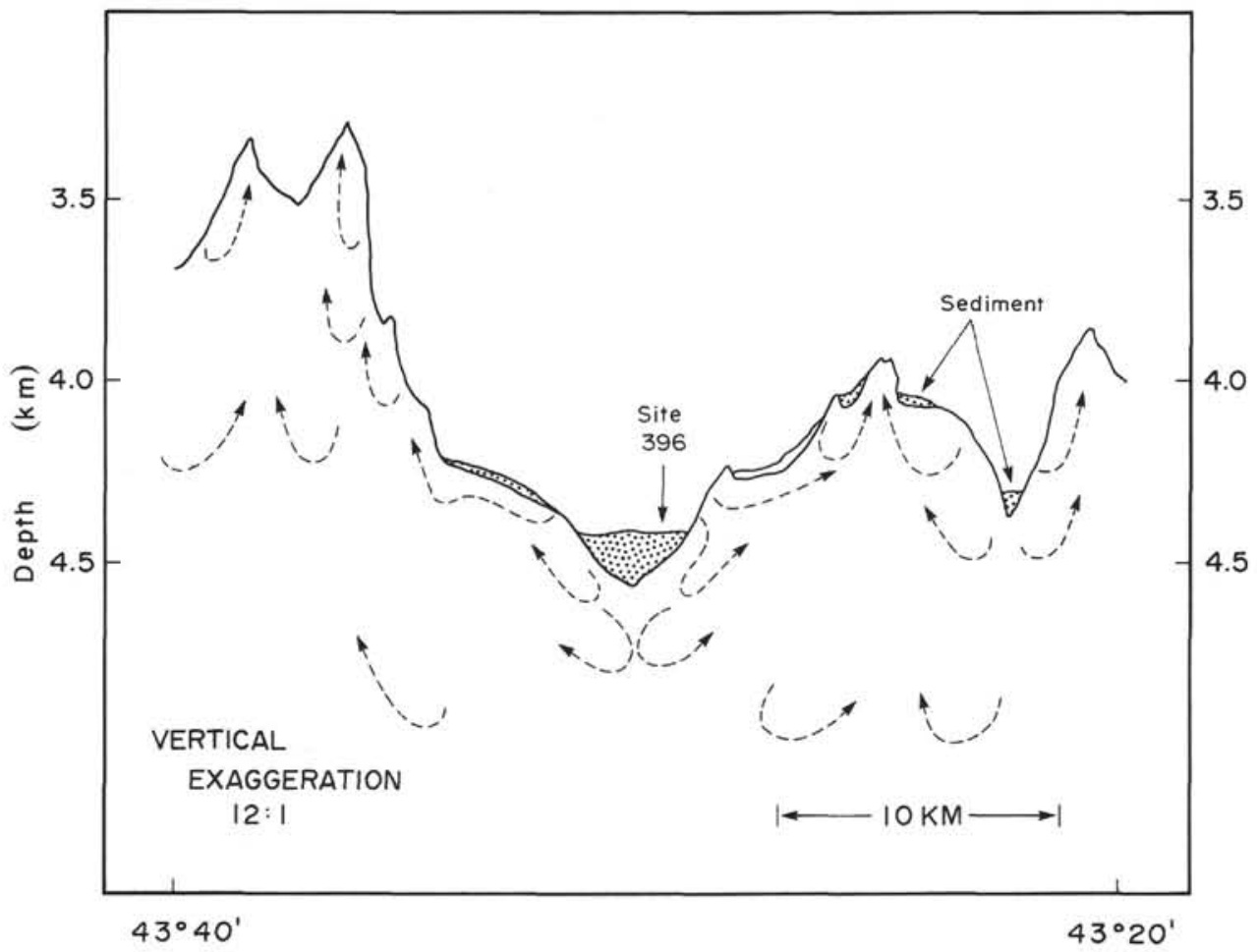

Figure 12. Profile across Site 396 showing sediment and illustrative patterns of water movement in the basaltic crust. 